\title{
Nanostructure Features, Phase Relationships and Thermoelectric Properties of Melt-Spun and Spark-Plasma-Sintered Skutterudites
}

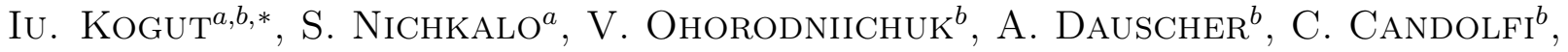 \\ P. MASSChelein ${ }^{b}$, A. JACQUOT ${ }^{c}$ AND B. LENOIR ${ }^{b}$ \\ ${ }^{a}$ Department of Semiconductor Electronics, Lviv Polytechnic National University, \\ 12 S. Bandery Str., 79013 Lviv, Ukraine \\ ${ }^{b}$ Institut Jean Lamour, UMR 7198 CNRS, Université de Lorraine, Parc de Saurupt, 54011 Nancy, France \\ ${ }^{c}$ Fraunhofer-Institut für Physikalische Messtechnik IPM, Heidenhofstr. 8, 79110 Freiburg, Germany
}

\begin{abstract}
Reduction of thermal conductivity remains a main approach relevant to enhancement of figure-of-merit of most thermoelectric materials. Melt spinning combined with spark plasma sintering appears to be a vital route towards fine-grain skutterudites with improved thermoelectric performance. However, upon high-temperature processing the $\mathrm{Fe}_{4-x} \mathrm{Co}_{x} \mathrm{Sb}_{12}$-based skutterudites are prone to decompose into multiple phases, which deteriorate their thermoelectric performance. In this study we addressed the effects of combined melt spinning and spark plasma sintering on the phase composition and microstructural properties of filled $\mathrm{Fe}_{4-x} \mathrm{Co}_{x} \mathrm{Sb}_{12}$ as well as their influence on thermoelectric characteristics of these compounds. The crystallites of filled $\mathrm{Fe}_{4-x} \mathrm{Co}_{x} \mathrm{Sb}_{12}$ were effectively reduced to sizes below $100 \mathrm{~nm}$ upon melt spinning, but also severe decomposition with weakly preserved nominal phase was observed. Spark plasma sintering of melt spun skutterudites resulted in even further reduction of crystallites. Upon short annealing and sintering the $n$-type materials easily restored into single-phase filled $\mathrm{CoSb}_{3} \mathrm{with}$ nanoscale features preserved, while secondary phases of $\mathrm{FeSb}_{2}$ and $\mathrm{Sb}$ remained in $p$-type compounds. Relatively high figure-of-merit $Z T_{\max }$ of 0.9 at $T \approx 400^{\circ} \mathrm{C}$ has been gained in nanostructured $\mathrm{Yb}_{x} \mathrm{Co}_{4} \mathrm{Sb}_{12}$, however, no significant reduction of thermal conductivity was observed. Abundant impurities in $p$-type filled $\mathrm{Fe}_{4-x} \mathrm{Co}_{x} \mathrm{Sb}_{12}$ led to drastic drop in their $Z T$, which even further degraded upon thermal cycling.
\end{abstract}

DOI: $10.12693 /$ APhysPolA.133.879

PACS/topics: 72.15.Eb, 72.15.Jf, 72.20.Pa, 66.70.Df, 81.20.Ev, 81.16.-c, 81.40.Gh

\section{Introduction}

Filled skutterudites with a general chemical formula $\mathrm{R}_{y} \mathrm{TM}_{4} \mathrm{Pn}_{12}$, where $\mathrm{R}$ stands for filler atoms (usually rare-earths), TM is transition metal ( $\mathrm{Fe}, \mathrm{Co}, \mathrm{Ni}$ ), and $\mathrm{Pn}$ are pnictogens (Sb, As, $\mathrm{P}$ ), belong to a class of high performance thermoelectric (TE) materials fulfilling the phonon-glass-electron-crystal concept [1]. Heavy filler atoms, inserted in the large voids of skutterudite unit cell, are weakly bound to a host structure and act as Einstein-like rattlers to effectively hinder the propagation of heat carrying phonons $[2,3]$. Thermal transport in $\mathrm{R}_{y} \mathrm{TM}_{4} \mathrm{Pn}_{12}$ is, thus, significantly reduced, which is a major prerequisite to their high figure-of-merit $Z T$. The latter can be further improved by nanostructuring, e.g. developed grain boundaries would enhance the scattering of phonons. A method based on melt spinning (MS, Fig. 1) combined with spark plasma sintering (SPS) enables the fine-grain nanostructure of TE materials and appears to be a viable route towards high- $Z T$ skutterudites $[4,5]$. Hitherto, the most studied and practically implemented in thermoelectric converters were $\mathrm{R}_{y} \mathrm{Fe}_{4-x} \mathrm{Co}_{x} \mathrm{Sb}_{12}$ skut-

*corresponding author; e-mail: gagatov@gmail.com terudites ( $x \leq 3.2$ results in $p$-type conductivity). However, their thermochemical stability remains a concern as upon heating they undergo peritectic decomposition yet in the temperature range of maximum TE efficiency. This stability is determined by the competition between formation of filled skutterudite and lower binary phases, which in turn depends, in particular, on the nature and fraction of filler atoms, $\mathrm{Fe} / \mathrm{Co}$ ratio, and synthesis and post-processing parameters [2, 6-8]. For instance, due to charge imbalance $\left(4 s^{2} 3 d^{6}\right.$ for Fe vs. $4 s^{2} 3 d^{7}$ for Co) the $\mathrm{Fe}_{4-x} \mathrm{Co}_{x} \mathrm{Sb}_{12}$ phase is metastable and easily decomposes upon heating. Full filling of lattice voids $(1 / 4$ $\mathrm{R}$ per $\mathrm{Fe}$ ) with tetravalent electropositive atoms could compensate that imbalance, but in fact the rare-earth atoms in $\mathrm{R}_{y} \mathrm{Fe}_{4-x} \mathrm{Co}_{x} \mathrm{Sb}_{12}$ attain only trivalent state; besides, their solubility rapidly diminishes with increasing Co fraction [2]. It appears that only partially filled and, thus, subject to decompose $\mathrm{R}_{y} \mathrm{Fe}_{4-x} \mathrm{Co}_{x} \mathrm{Sb}_{12}$ can be fabricated. In this concern, the present research aimed on the study of the effect of high-temperature post-processing, such as MS and SPS, on the development of nanostructural features and secondary phases in $\mathrm{Fe}_{4-x} \mathrm{Co}_{x} \mathrm{Sb}_{12}$-based filled skutterudites and on the assessment of the effect of said features, decomposition and treatment on their thermoelectric properties. 

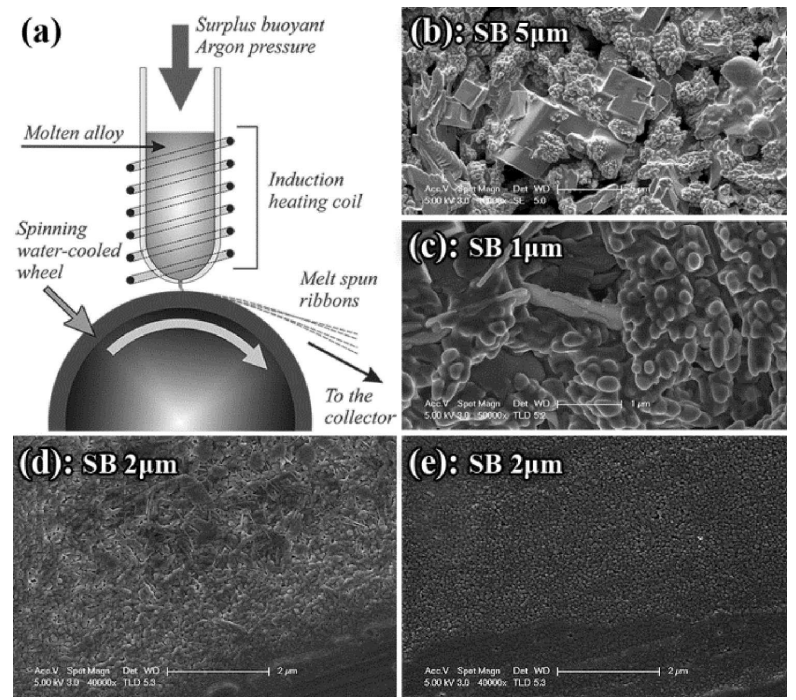

Fig. 1. Schematic view of MS technique (a) and SEM micrographs of nanoscale features in as-spun $\mathrm{Ce}_{0.85} \mathrm{Fe}_{3.5} \mathrm{Co}_{0.5} \mathrm{Sb}_{12}$ ribbons on free $(\mathrm{b}, \mathrm{c})$ and contact (d, e) surfaces. SB stands for scale bar size.

\section{Experimental details}

Elemental In (99.999\% purity), Ce and $\mathrm{Yb}$ (both $>99 \%$ ) fillers were mixed with Co (>99.95\%), Fe $(>99.5 \%)$ and $\mathrm{Sb}(99.999 \%)$ in stoichiometric ratios and sealed in carbon coated quartz tubes for synthesis of filled skutterudites using traditional melting-quenchingannealing (MQA) approach. For $p$-types, prior to MQA, the $\mathrm{Ce}$, $\mathrm{Co}$, and $\mathrm{Fe}$ were alloyed by induction melting and pulverized in order to homogenize the compound and avoid extensive $\mathrm{Ce}+\mathrm{Sb}$ reactions. After melting for $96 \mathrm{~h}$ and quenching the ingots were ground into fine powders by ball milling, annealed for another $96 \mathrm{~h}$, and then milled again. Both melting $\left(T_{m}\right)$ and annealing $\left(T_{a}\right)$ temperatures were $650^{\circ} \mathrm{C}$, but for $\mathrm{Yb}_{y} \mathrm{Co}_{4} \mathrm{Sb}_{12}$ the $T_{m}$ was $750^{\circ} \mathrm{C}$. The treatment conditions were based on the reported phase equilibria studies in $\mathrm{R}-\mathrm{Fe}-\mathrm{Co}-\mathrm{Sb}$ systems: existence of stable single phases of $\mathrm{Yb}_{y} \mathrm{Co}_{4} \mathrm{Sb}_{12}$ and $\mathrm{In}_{y} \mathrm{Co}_{4} \mathrm{Sb}_{12}$ with maximum filling ratio within $773-$ $1073 \mathrm{~K} \mathrm{[8]} \mathrm{and} \mathrm{748-973} \mathrm{K} \mathrm{[9],} \mathrm{respectively,} \mathrm{and} \mathrm{forma-}$ tion of $\mathrm{R}_{y} \mathrm{Fe}_{4-x} \mathrm{Co}_{x} \mathrm{Sb}_{12}$ within 898-973 K [10, 11]. We used also $p$-type precursor $\mathrm{Mm}_{0.9} \mathrm{Fe}_{3} \mathrm{CoSb}_{12}$ nanopowders from commercial supplier (Matres scrl, Italy; Mm stands for misch-metal, a Ce:La mixture). Finally, pulverized skutterudites were consolidated into $\phi 12 \mathrm{~mm}$ pellets by SPS (Dr.Sinter 515S) under primary vacuum $(6 \mathrm{~Pa})$ at sintering temperature $T_{s}=620^{\circ} \mathrm{C}$, uniaxial pressure of $50 \mathrm{MPa}$ and soaking time of 5-10 min. For nanostructuring the skutterudite samples were meltspun. The starting batch was induction melted in quartz tube with a $\emptyset 0.5 \mathrm{~mm}$ nozzle on its tip and, once completely liquefied, ejected onto the spinning watercooled copper wheel by applying the surplus Ar pressure at the tube opening (Fig. 1a). The temperature of melt was pyrometer-controlled, its saturation indicated in completely liquid batch. For $n$-types $T_{m}$ exceeded $1000-1100^{\circ} \mathrm{C}$, while for Fe-substituted compounds it was $700-1000^{\circ} \mathrm{C}$. Rapid quenching upon MS favored nonequilibrium solidification of liquid in a form of thin ribbons with developed nanoscale features (Fig. 1b-e). The as-spun ribbons were sintered in SPS with an intermediary step of annealing at $T_{a}<T_{s}$.

The developed samples were characterized by powder X-ray diffraction (PXRD, Bruker D8 Advance, $\mathrm{Cu} K_{\alpha_{1}}$ radiation) and scanning electron microscope (SEM, Philips XL30 SFEG). The Rietveld refinement of PXRD curves and the Williamson-Hall (WH) plot method were used for evaluation of crystallographic parameters, phase composition, microstrain and crystallite dimensions (reliabilities of fit, reduced $\chi^{2}$, did not exceed 5.0, and for WH the uncertainty did not exceed $6 \%$ ). NBS Silicon-1 standard was used for accounting of instrumental broadening of XRD peaks. Electrical conductivity $\sigma(T)$ and thermopower $S(T)$ of $2 \times 2 \times 12 \mathrm{~mm}^{3}$ skutterudite samples were measured by a four-probe method realized in Ulvac Riko ZEM-3 setup. Also $1.2 \mathrm{~mm}$ thick $\emptyset 12 \mathrm{~mm}$ disks were cut for measurements of thermal diffusivity $\alpha(T)$ by means of laser flash method (Netzsch LFA 427$)$. Total thermal conductivity $\kappa(T)$ was then derived

$$
\kappa(T)=\alpha(T) c_{p} d,
$$

where $c_{p}$ is the Dulong-Petit law constrained heat capacity and $d$ is the experimental density of sintered ingots.

\section{Results and discussion}

\subsection{Effects of SPS and melt-spinning on microstructure and phase composition of $\mathrm{R}_{y} \mathrm{Fe}_{4-x} \mathrm{Co}_{x} \mathrm{Sb}_{12}$}

Nearly perfect polycrystalline skutterudite phase (96.0-99.2 wt\%) formed in all traditionally, i.e. MQA, synthesized $\mathrm{R}_{y} \mathrm{Fe}_{4-x} \mathrm{Co}_{x} \mathrm{Sb}_{12}$ (Fig. 2, Table I). Upon SPS the $p$-type compounds decomposed into $\mathrm{R}_{y} \mathrm{Fe}_{4-x} \mathrm{Co}_{x} \mathrm{Sb}_{12}$ and secondary phases of $\mathrm{FeSb}_{2}(9-12 \%)$ and pure $\mathrm{Sb}$ (1.8-5.0\%), while in Fe-free $n$-types the nominal phase even improved, before and after SPS yielding impurities of $\mathrm{InSb}\left(2.1 \%\right.$ vs. $0.6 \%$, respectively), $\mathrm{In}_{2} \mathrm{O}_{3}$ (1.7\% vs. $1.3 \%$ ) for $\mathrm{In}_{0.4} \mathrm{Co}_{4} \mathrm{Sb}_{12}$, and $\mathrm{Sb}(1.0-1.5 \%), \mathrm{Yb}_{2} \mathrm{O}_{3}$ and $\mathrm{YbSb}_{2}$ for $\mathrm{Yb}_{0.2} \mathrm{Co}_{4} \mathrm{Sb}_{12}$. Spark plasma sintering also featured structural changes of skutterudites, namely, reduction of lattice constant and average crystallite dimensions, and development of grain internal microstrain.

Melt spinning of $\mathrm{R}_{y} \mathrm{Fe}_{4-x} \mathrm{Co}_{x} \mathrm{Sb}_{12}$ resulted in solidification of thin multiphase (Fig. 3) ribbons with developed nanoscale features of various morphologies (Figs. 1be). In $n$-type skutterudites the detected phases were nominal $\mathrm{R}_{y} \mathrm{Co}_{4} \mathrm{Sb}_{12}$ (Table I), prevailing $\mathrm{CoSb}_{2}$ (up to $51.6 \%$ and $33.8 \%$ for $\mathrm{In}_{y} \mathrm{Co}_{4} \mathrm{Sb}_{12}$ and $\mathrm{Yb}_{y} \mathrm{Co}_{4} \mathrm{Sb}_{12}$, respectively) and $\mathrm{Sb}(23 \%$ and $14.7 \%), \mathrm{CoSb}$ (17.4\% and $9.3 \%$ ) and possible minor $\mathrm{RSb}_{x}$. Up to $58.2 \%$ and $39 \%$ of $\mathrm{FeSb}_{2}, 24.6 \%$ and $13.4 \%$ of pure $\mathrm{Sb}$, and $16.4 \%$ and 

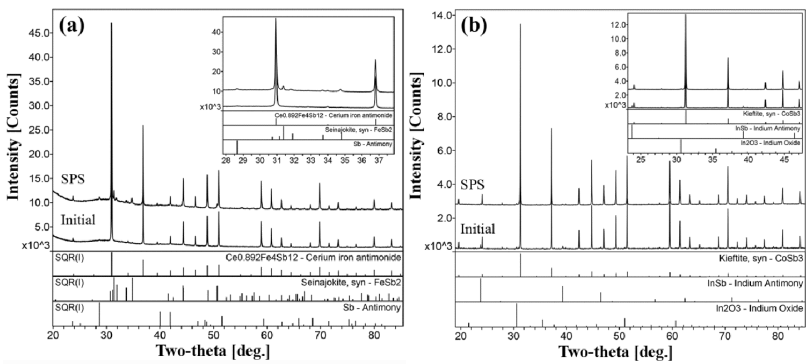

Fig. 2. Typical X-ray diffractograms of $p$-type ((a), $\left.\mathrm{Ce}_{0.85} \mathrm{Fe}_{3.5} \mathrm{Co}_{0.5} \mathrm{Sb}_{12}\right)$ and $n$-type ((b), $\left.\mathrm{In}_{0.4} \mathrm{Co}_{4} \mathrm{Sb}_{12}\right)$ skutterudites before and after SPS processing.

$13.7 \% \mathrm{FeSb}$ phases have been detected in melt spun $p$ type $\mathrm{Ce}_{y} \mathrm{Fe}_{4-x} \mathrm{Co}_{x} \mathrm{Sb}_{12}$ and $\mathrm{Mm}$-filled $\mathrm{Fe}_{4-x} \mathrm{Co}_{x} \mathrm{Sb}_{12}$, respectively. Higher amounts of skutterudite phase were detected at contact surfaces of both $n$ - and $p$-type MS ribbons, and more of secondary phases were inherent for free surfaces, which is obviously a consequence of nonuniform cooling rates over the ribbon thickness. Interestingly, in $\mathrm{Ce}_{0.85} \mathrm{Fe}_{3.5} \mathrm{Co}_{0.5} \mathrm{Sb}_{12}$, melt-spun at $703^{\circ} \mathrm{C}$ (MS2 in Fig. 3a), only minor formation of $\mathrm{FeSb}_{x}$ has been discovered, while $65 \%$ of skutterudite phase was maintained along with $24 \%$ of $\mathrm{Sb}$. This is explained by the vicinity of $T_{m}$ to peritectic decomposition point and assumes that such decomposition onsets with abundant $\mathrm{Sb}$ dissociation followed by precipitation of $\mathrm{FeSb}_{2}$. The temperature of peritectic decomposition for $\mathrm{R}_{y} \mathrm{Fe}_{4-x} \mathrm{Co}_{x} \mathrm{Sb}_{12}$ is in the range of $600-850{ }^{\circ} \mathrm{C}$, depending on the actual composition, and tends to decrease with cobalt content [11-13].
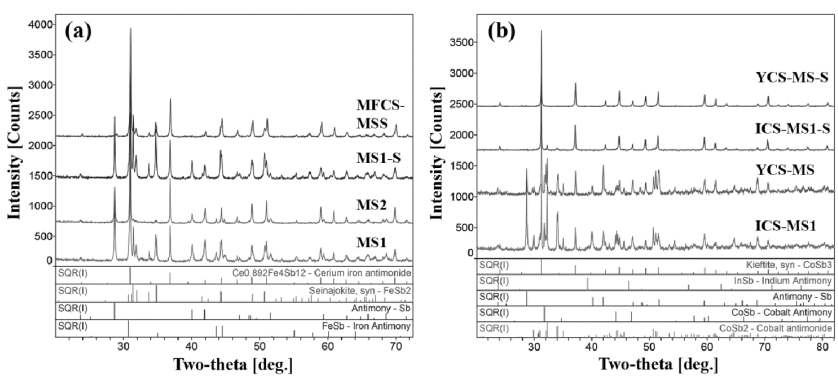

Fig. 3. X-ray diffractograms of melt-spun skutterudite samples: (a) $\mathrm{Ce}_{0.85} \mathrm{Fe}_{3.5} \mathrm{Co}_{0.5} \mathrm{Sb}_{12}\left(\mathrm{MS} 1-T_{m}>810^{\circ} \mathrm{C}\right.$, MS2 - $T_{m}=703{ }^{\circ} \mathrm{C}$, and MS1-S after SPS) and $\mathrm{Mm}_{0.9} \mathrm{Fe}_{3} \mathrm{CoSb}_{12}$ (MFCS-MSS - after SPS); (b) $\mathrm{In}_{0.4} \mathrm{Co}_{4} \mathrm{Sb}_{12}$ (before, ICS-MS1, and after SPS, ICSMS1-S) and $\mathrm{Yb}_{0.3} \mathrm{Co}_{4} \mathrm{Sb}_{12}$ (before and after SPS, respectively).

According to both the XRD and SEM-EDS (energydispersive X-ray spectroscopy) studies, MS favored the substantial reduction of average dimensions of the nominal phase crystallites to sub-100 $\mathrm{nm}$ range (Table I, Fig. 1d-e). EDS confirmed the presence of all con- stituents of $\mathrm{R}_{y} \mathrm{Fe}_{4-x} \mathrm{Co}_{x} \mathrm{Sb}_{12}$ in MS ribbons and a skutterudite phase predominantly solidified on their contact surface. The free surface contained nanoscale features of various morphologies (Fig. 1b-c for $p$-types) with roughly $\mathrm{Fe}_{1-x} \mathrm{Co}_{x} \mathrm{Sb}_{2}$ principal composition of "grapelike" agglomerations, in which "bubbles" were closer to $(\mathrm{Fe} / \mathrm{Co}) \mathrm{Sb}$, and nanoflakes majorly composed of Sb. Larger micron-scale cubes revealed a Ce-filled skutterudite phase, depleted in cerium and $\mathrm{Sb}$ rich.

Developed grain boundaries in the MS skutterudite ribbons favored fast solid-state diffusion resulting in rapid phase transformations and strong healing effect upon just short time spark plasma sintering. SPS of $n$ type $\mathrm{R}_{y} \mathrm{Co}_{4} \mathrm{Sb}_{12}$ with a 10 min step of annealing at $400^{\circ} \mathrm{C}$ followed by $5 \mathrm{~min}$ long sintering at $620^{\circ} \mathrm{C}$ yielded $88.2 \%$ skutterudite phase along with $11 \%$ of $\mathrm{CoSb}_{2}$ and $0.8 \%$ $\mathrm{Sb}$ in $\mathrm{In}_{0.4} \mathrm{Co}_{4} \mathrm{Sb}_{12}$ (MS1). The increase of $T_{a}$ to $560{ }^{\circ} \mathrm{C}$ resulted in higher ratio of phase transformations with only $8.4 \%$ of $\mathrm{CoSb}_{2}$ remaining in $\mathrm{In}_{0.4} \mathrm{Co}_{4} \mathrm{Sb}_{12}$ (MS2). At optimized SPS parameters $\left(10 \mathrm{~min}\right.$ annealing at $580^{\circ} \mathrm{C}$ and 5 min sintering at $620^{\circ} \mathrm{C}$ ) single skutterudite phase formed in $n$-type MS skutterudites, e.g. in $\mathrm{Yb}_{0.3} \mathrm{Co}_{4} \mathrm{Sb}_{12}$ (Table I). Worth noting, the trend towards diminishing of the average crystallite dimensions and development of structural microstrain, accompanied by decrease of lattice parameter, holds also for SPS of melt-spun skutterudites. In principle, $a_{300 K}$ of filled skutterudites should obey the Vegard law, i.e. it should increase with the filling fraction linearly $[8,9]$. Likewise, the lattice would expand with iron content, and multiple filling should lead to further expansion of the unit cell due to variation in atomic radii of constituent elements. As follows from Table I, this trend is not evident. Refinement of atomic occupancies for two reference samples, $\mathrm{In}_{0.4} \mathrm{Co}_{4} \mathrm{Sb}_{12}$ and $\mathrm{Ce}_{0.85} \mathrm{Fe}_{3.5} \mathrm{Co}_{0.5} \mathrm{Sb}_{12}$, has shown the actual composition different $\left(\mathrm{In}_{0.15} \mathrm{Co}_{4} \mathrm{Sb}_{11.93}\right.$ and $\mathrm{Ce}_{0.82} \mathrm{Fe}_{3.48} \mathrm{Co}_{0.52} \mathrm{Sb}_{11.95}$, respectively) from that nominal, however, it did not change or even improved upon SPS $\left(\mathrm{In}_{0.16} \mathrm{Co}_{4} \mathrm{Sb}_{12.11}\right.$ and $\left.\mathrm{Ce}_{0.83} \mathrm{Fe}_{3.48} \mathrm{Co}_{0.52} \mathrm{Sb}_{12.00}\right)$. Thus, the observed variations of lattice constants and satellite microstrains along with crystallites reduction are, likely, related to peculiar features of SPS technique (e.g., high-energy pulses and high isostatic pressures), which have to be yet clarified. One should, however, not exclude the effect of skutterudite phase decomposition upon melt-spinning.

In general, SPS seems to favor the development and preserving of the nanostructure of melt spun skutterudites, as well as improvement of their phase compositions. For instance, out of the above trend, in $\mathrm{In}_{0.4} \mathrm{Co}_{4} \mathrm{Sb}_{12}$ the unit cell parameter greatly increased, suggesting nearly full occupancy of the lattice voids, that approaches solubility limit for indium in $\mathrm{CoSb}_{3}$ matrix [14], though nominal content of In was higher. Presumably the residuals of indium in the form of $\operatorname{In}_{2} \mathrm{O}_{3}$ were ejected from the melt during MS, while phase reconfiguration between InSb and $\mathrm{In}_{y} \mathrm{Co}_{4} \mathrm{Sb}_{12}$ occurred. On the other hand, substitution of $\mathrm{Sb}$ for In could have taken place [9, 14-15]. Assuming the $\operatorname{In}_{y} \mathrm{Co}_{4}\left(\mathrm{Sb}_{1-z} \mathrm{In}_{z}\right)_{12}$ model, i.e. In atoms share 
24c Wyckoff positions with Sb, the Rietveld refinement for MS2 sample after SPS yielded actual composition of $\mathrm{In}_{0.25} \mathrm{Co}_{4} \mathrm{Sb}_{11.66} \mathrm{In}_{0.18}$, which is fairly consistent with the nominal composition of starting material and empiric dependence of $a_{300 K}$ on In-content, reported in [9]. Obviously, the healing effect of short MS-SPS processing led to reconfiguration of nominal phase in $n$-type materials. This is clear for $\mathrm{Yb}_{0.3} \mathrm{Co}_{4} \mathrm{Sb}_{12}$ compound, which has been
MQA-synthesized at, likely, insufficient $T_{m}\left(750^{\circ} \mathrm{C}\right)$, so that $\mathrm{Yb}$ weakly inserted in the voids $\left(a_{300 K}\right.$ comparable to pure unfilled $\left.\mathrm{CoSb}_{3}[1]\right)$. After MS the lattice parameter for this compound greatly increased suggesting improved filling of lattice voids. Improvement of skutterudite phase in MS-SPS $\mathrm{Yb}_{0.3} \mathrm{Co}_{4} \mathrm{Sb}_{12}$ is evidenced also by optimized thermoelectric properties, discussed below.

TABLE I

Nominal compositions and X-ray characteristics of $\mathrm{R}_{y} \mathrm{Fe}_{4-x} \mathrm{Co}_{x} \mathrm{Sb}_{12}$ samples.

\begin{tabular}{l|cccc|cccc}
\hline \hline \multirow{2}{*}{ Composition } & \multicolumn{4}{|c|}{ Before SPS } & \multicolumn{4}{c}{ After SPS } \\
\cline { 2 - 8 } & $a_{300 K}[\AA]$ & $r[\mathrm{~nm}]$ & $\varepsilon[\%]$ & $n[\%]$ & $a_{300 K}[\AA]$ & $r[\mathrm{~nm}]$ & $\varepsilon[\%]$ & $n[\%]$ \\
\hline $\mathrm{In}_{0.4} \mathrm{Co}_{4} \mathrm{Sb}_{12}$ & $9.0485(1)$ & $162.4(2.0)$ & $0.046(1)$ & 96.3 & $9.0476(1)$ & $100.5(0.4)$ & $0.078(1)$ & 98.2 \\
$\mathrm{In}_{0.4} \mathrm{Co}_{4} \mathrm{Sb}_{12}(\mathrm{MS} 1)$ & $9.0443(4)$ & $62.1(1.8)$ & $0.192(6)$ & 22.3 & $9.0513(2)$ & $47.5(0.5)$ & $0.221(2)$ & 88.2 \\
$\mathrm{In}_{0.4} \mathrm{Co}_{4} \mathrm{Sb}_{12}(\mathrm{MS} 2)$ & $9.0425(6)$ & $107.0(3.1)$ & $\mathrm{n} / \mathrm{a}$ & 9.4 & $9.0536(2)$ & $49.9(0.4)$ & $0.207(2)$ & 91.6 \\
$\mathrm{Yb}_{0.3} \mathrm{Co}_{4} \mathrm{Sb}_{12}$ & $9.0350(1)$ & $95.5(0.4)$ & $0.096(1)$ & 96.8 & $9.0370(2)$ & $71.6(0.4)$ & $0.202(2)$ & 96.6 \\
$\mathrm{Yb}_{0.3} \mathrm{Co}_{4} \mathrm{Sb}_{12}(\mathrm{MS})$ & $9.0475(6)$ & $41.1(1.1)$ & $0.200(5)$ & 37.6 & $9.0426(2)$ & $78.5(0.6)$ & $0.189(2)$ & 99.2 \\
$\mathrm{Yb}_{0.2} \mathrm{Co}_{4} \mathrm{Sb}_{12}$ & $9.0432(1)$ & $83.2(0.4)$ & $0.086(1)$ & 97.4 & $9.0422(2)$ & $63.1(0.7)$ & $0.151(2)$ & 99.0 \\
$\mathrm{Ce}_{0.85} \mathrm{Fe}_{3.5} \mathrm{Co}_{0.5} \mathrm{Sb}_{12}$ & $9.1259(1)$ & $106.9(0.5)$ & $0.083(1)$ & 99.2 & $9.1248(1)$ & $78.6(0.5)$ & $0.099(1)$ & 87.2 \\
$\mathrm{Ce}_{0.85} \mathrm{Fe}_{3.5} \mathrm{Co}_{0.5} \mathrm{Sb}_{12}(\mathrm{MS} 1)$ & $9.1270(5)$ & $47.0(1.2)$ & $0.174(5)$ & 31.0 & $9.1250(3)$ & $36.1(0.6)$ & $0.240(4)$ & 40.8 \\
$\mathrm{Ce}_{0.85} \mathrm{Fe}_{3.5} \mathrm{Co}_{0.5} \mathrm{Sb}_{12}(\mathrm{MS} 2)$ & $9.1252(2)$ & $57.4(1.0)$ & $0.140(3)$ & 64.9 & - & - & - & - \\
$\mathrm{Mm}_{0.9} \mathrm{Fe}_{3} \mathrm{CoSb}_{12}$ & - & - & - & - & $9.1140(5)$ & $43.7(0.6)$ & $0.236(3)$ & 84.8 \\
$\mathrm{Mm}_{0.9} \mathrm{Fe}_{3} \mathrm{CoSb}_{12}(\mathrm{MS})$ & $9.1140(3)$ & $70.5(1.8)$ & $0.146(4)$ & 36.5 & $9.1075(2)$ & $46.0(0.8)$ & $0.197(3)$ & 69.1 \\
\hline
\end{tabular}

Here $a_{300 K}$ is the lattice parameter, $r$ is the crystallite average dimension, $\varepsilon$ is internal microstrain, and $n$ is the amount of nominal phase.

Values in parentheses stand for uncertainty (consider last digits for lattice parameters and microstrains).

Though phase transformations took place also during SPS of $p$-type $\mathrm{R}_{y} \mathrm{Fe}_{4-x} \mathrm{Co}_{x} \mathrm{Sb}_{12} \mathrm{MS}$ ribbons, the nominal phase has not been successfully healed in them. The amount of both $\mathrm{R}_{y} \mathrm{Fe}_{4-x} \mathrm{Co}_{x} \mathrm{Sb}_{12}$ and $\mathrm{FeSb}_{2}$ improved at an expense of free $\mathrm{Sb}$ and $\mathrm{FeSb}$, but the final content of nominal phase did not exceed $69 \%$ even at optimized SPS conditions (MFCS-MSS in Fig. 3a). Except for $\mathrm{Mm}_{0.9} \mathrm{Fe}_{3} \mathrm{CoSb}_{12}$, the lattice parameters for MS-SPS $p$-types remained unchanged as compared to traditionally synthesized $\mathrm{R}_{y} \mathrm{Fe}_{4-x} \mathrm{Co}_{x} \mathrm{Sb}_{12}$, implying same reconfiguration of skutterudite phase, as was observed for $n$-type compounds.

\subsection{Thermoelectric properties of melt-spun and traditionally synthesized $R_{y} \mathrm{Fe}_{4-x} \mathrm{Co}_{x} S b_{12}$}

Comparison of thermoelectric properties for MS and traditionally synthesized skutterudites is presented in Fig. 4. Unfortunately, nanostructuring did not lead to a desired reduction in total thermal conductivity of $n$ - and $p$-type $\mathrm{R}_{y} \mathrm{Fe}_{4-x} \mathrm{Co}_{x} \mathrm{Sb}_{12}$. Values and temperature dependences of $\kappa(T)$ for $\mathrm{MS} \mathrm{Yb}_{0.3} \mathrm{Co}_{4} \mathrm{Sb}_{12}$ and $\mathrm{In}_{0.4} \mathrm{Co}_{4} \mathrm{Sb}_{12}$ are comparable to those of traditionally processed $n$-type $\mathrm{R}_{y} \mathrm{Fe}_{4-x} \mathrm{Co}_{x} \mathrm{Sb}_{12}$, while $\kappa(T)$ of MSSPS $\mathrm{Mm}_{0.9} \mathrm{Fe}_{3} \mathrm{CoSb}_{12}$ was even $30 \%$ higher than that for its non-MS counterparts of comparable chemical composition. Obviously, abundant formation of secondary phases in MS-SPS $\mathrm{Mm}_{0.9} \mathrm{Fe}_{3} \mathrm{CoSb}_{12}$ resulted in much lower Seebeck coefficient (thermopower) and higher resistivity, yielding in total very low $Z T_{\max }$ of $\approx 0.12$. Upon thermal cycling (second run) its thermoelectric properties further deteriorated. Meanwhile, we detected only minor degradation of thermoelectric performances upon successive measurements for traditionally synthesized $p$ type skutterudites. Hence, the MS-SPS process for highefficiency $p$-type thermoelectric skutterudites would require substantial optimization in order to minimize the effect of, likely, inevitable secondary phases on their thermoelectric properties. On the other hand, healing effect of MS-SPS processing is clearly evidenced in Ybfilled $n$-type skutterudites. Due to not optimal synthesis conditions the actual filling ratio in as-synthesized $\mathrm{Yb}_{0.3} \mathrm{Co}_{4} \mathrm{Sb}_{12}$ was very small, which resulted in structural, transport and thermoelectric properties comparable to those inherent for unfilled $\mathrm{CoSb}_{3}$ [1]. For comparison, structural data and temperature dependences of transport properties for another properly synthesized $\mathrm{Yb}_{0.2} \mathrm{Co}_{4} \mathrm{Sb}_{12}$ (traditional MQA, $T_{m}=1150^{\circ} \mathrm{C}$ for $3 \mathrm{~h}$, $T_{a}=650{ }^{\circ} \mathrm{C}$ for $168 \mathrm{~h}$; the studies beyond the focus of this paper) are appended in Table I and Fig. 4. For both non-MS samples a semiconductor-like behavior of $\rho(T)$ was inherent. Meanwhile, after MS-SPS the lattice constant of $\mathrm{Yb}_{0.3} \mathrm{Co}_{4} \mathrm{Sb}_{12}$ was comparable to that of traditional $\mathrm{Yb}_{0.2} \mathrm{Co}_{4} \mathrm{Sb}_{12}$, suggesting similar filling ratios. Furthermore, thermoelectric performances of MSSPS sample were much optimized as compared to traditional $\mathrm{Yb}_{0.2} \mathrm{Co}_{4} \mathrm{Sb}_{12}$, resulting in low values and metalliclike behavior of resistivity, while attaining the same high values of thermopower. Despite the relatively high total thermal conductivity, substantial improvement of 
$Z T$ has been achieved in it, yielding $Z T_{\max }$ of 0.9 at $T \approx 400^{\circ} \mathrm{C}$. Thus, combined MS-SPS process appears to be a fast and reliable route towards high-quality and high-performance thermoelectric skutterudites, provided that optimum doping and process conditions are chosen.
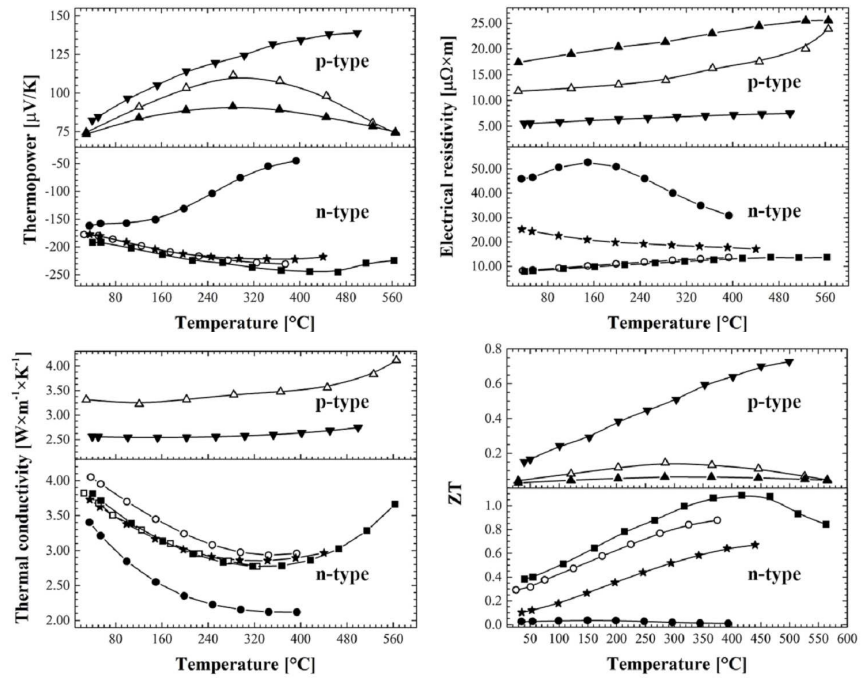

Fig. 4. Comparison of thermoelectric and transport properties of MS-SPS (open symbols) and traditionally (solid symbols) synthesized $\mathrm{R}_{y} \mathrm{Fe}_{4-x} \mathrm{Co}_{x} \mathrm{Sb}_{12}$ : squares - $\mathrm{In}_{0.4} \mathrm{Co}_{4} \mathrm{Sb}_{12}$, circles - $\mathrm{Yb}_{0.3} \mathrm{Co}_{4} \mathrm{Sb}_{12}$ (thermal conductivity values for non-MS are multiplied by 0.5 to fit in plot), stars - traditional optimized MQA-SPS $\mathrm{Yb}_{0.2} \mathrm{Co}_{4} \mathrm{Sb}_{12}$, up-triangles - MS $\mathrm{Mm}_{0.9} \mathrm{Fe}_{3} \mathrm{CoSb}_{12}$ after first (open) and second (solid) cycle, down-triangles - traditional MQA-SPS $\mathrm{Ce}_{0.85} \mathrm{Fe}_{3.5} \mathrm{Co}_{0.5} \mathrm{Sb}_{12}$.

\section{Conclusions}

The study of combined action of melt spinning and spark plasma sintering on phase composition, microstructural and thermoelectric properties of filled skutterudites has been performed. Melt spinning allowed for reduction of the $\mathrm{R}_{y} \mathrm{Fe}_{4-x} \mathrm{Co}_{x} \mathrm{Sb}_{12}$ crystallites to sizes well below $100 \mathrm{~nm}$, but also led to drastic deterioration of nominal phase in these compounds. Facilitated by enhanced finegrain structure of as-melt-spun ribbons, SPS appears to enable an easy and fast restoration of $\mathrm{R}_{y} \mathrm{Fe}_{4-x} \mathrm{Co}_{x} \mathrm{Sb}_{12}$ phase with preserved nanostructure in them and relatively high TE performances. Due to peculiar events and process features of SPS, that have to be yet clarified, the observed transformations of $\mathrm{R}_{y} \mathrm{Fe}_{4-x} \mathrm{Co}_{x} \mathrm{Sb}_{12}$ are accompanied by contraction of unit cell, development of structural microstrains and reduction of crystallite sizes. Although the expected nanostructure-related reduction of thermal conductivity has not been proven, this study inferred the attractiveness of simple MS-SPS approach in concern of time and cost efficiency of TE technology for energy applications. However, significant process optimization would be required for metastable by nature Fesubstituted $p$-type skutterudites in order to minimize the deteriorating effect of, likely, inevitable secondary phases on their thermoelectric properties.

\section{References}

[1] G.S. Nolas, D.T. Morelli, T.M. Tritt, Ann. Rev. Mater. Res. 29, 89 (1999).

[2] C. Uher, in: Thermoelectrics Handbook: Macro to Nano, Eds. D.M. Rowe, Taylor \& Francis Group, Boca Raton 2006, p. 34-1.

[3] E. Alleno, D. Bérardan, C. Godart, M. Puyet, B. Lenoir, R. Lackner, E. Bauer, L. Girard, D. Ravot, Physica B 383, 103 (2006).

[4] H. Li, X. Tang, Q. Zhang, C. Uher, Appl. Phys. Lett. 93, 252109 (2008).

[5] G. Tan, W. Liu, S. Wang, Y. Yan, H. Li, X. Tang, C. Uher, J. Mater. Chem. A 1, 12657 (2013).

[6] Z. Chen, J. Yang, R. Liu, L. Xi, W. Zhang, J. Yang, J. Electron. Mater. 42, 2492 (2013).

[7] A. Sesselmann, G. Skomedal, H. Middleton, E. Müller, J. Electron. Mater. 45, 1397 (2016).

[8] Y. Tang, S. Chen, G.J. Snyder, J. Materiomics 1, 75 (2015).

[9] A. Grytsiv, P. Rogl, H. Michor, E. Bauer, G. Giester, J. Electron. Mater. 42, 2940 (2013).

[10] V. Raghavan, J. Phase Equilibria 22, 666 (2001).

[11] D. Bérardan, C. Godart, E. Alleno, E. Leroy, P. Rogl, J. Alloys Comp. 350, 30 (2003).

[12] D. Bérardan, E. Alleno, C. Godart, O. Rouleau, J. Rodriguez-Carvajal, Mater. Res. Bull. 40, 537 (2005).

[13] D. Bérardan, C. Godart, E. Alleno, St. Berger, E. Bauer, J. Alloys Comp. 351, 18 (2003).

[14] Y. Tang, Y. Qiu, L. Xi, X. Shi, W. Zhang, L. Chen, S.M. Tseng, S. Chen, G.J. Snyder, Energy Environ. Sci. 7, $812(2014)$.

[15] G. Rogl, A. Grytsiv, K. Yubuta, S. Puchegger, E. Bauer, C. Raju, R.C. Mallik, P. Rogl, Acta Mater. 95, 201 (2015). 